\title{
EL CONCEPTO DE MINORÍA POLÍTICO-ELECTORAL EN LA DEMOCRACIA REPRESENTATIVA DE LA CONSTITUCIÓN DE 1991
}

Carlos Arturo Duarte Martínez*

Recibido: Julio 6 de 2014

Aprobado: Septiembre 10 de 2014

\section{RESUMEN}

Se analizan los pronunciamientos emitidos por la Corte Constitucional y el Consejo de Estado sobre los partidos y movimientos minoritarios para construir un concepto de minoría política en la democracia representativa. Desde un punto de vista hermenéutico se analiza la controversia surgida dentro del Consejo de Estado en torno al tema. Esta Corte considera que en el sistema jurídico colombiano minoría política es equivalente a la oposición política. Por su parte, la Corte Constitucional entiende que ser minoría política es independiente a la posición política que se asuma frente al Gobierno. Se concluye de estas decisiones la existencia de un concepto cuantitativo, subjetivo y variable de minoría político-electoral.

Palabras Clave: Democracia representativa, exégesis, interpretación sistemática, minoría político-electoral.

\footnotetext{
* Abogado, Especialista en Derecho Público. Docente Auxiliar de la Universidad Autónoma de Bucaramanga. Miembro del Grupo de Investigación en Hermenéutica Jurídica adscrito al Centro de Investigaciones Socio-Jurídicas “Laureano Gómez Serrano”. Correo electrónico: cduarte3@unab.edu.co
} 


\title{
THE CONCEPT OF ELECTORAL POLITICAL MINORITY WITHIN THE REPRESENTATIVE DEMOCRACY OF THE 1991 CONSTITUTION
}

\begin{abstract}
This article focuses on the statements issued by the Constitutional Court and the Council of State regarding parties and minority movements in order to conceptualize a political minority within the representative democracy. The controversy arisen in relation to this topic within the Council of State, is analyzed from a hermeneutic perspective. As a matter of fact, this Court considers that political minority is equivalent to political opposition within the Colombian legal system. On the other side, the Constitutional Court states that the status of a political minority is independent from the political position towards Government. These statements reveal the existence of a quantitative, subjective and variable concept of an electoral political minority.
\end{abstract}

Key words: Representative democracy, exegesis, systematic interpretation, political electoral minority.

A Solange Blanco Villamizar y a mis compañeros

del Tribunal Administrativo de Santander, por los conocimientos compartidos y la experiencias vividas.

\section{INTRODUCCIÓN}

Se anunció que en las elecciones legislativas de 2014, los partidos y movimientos políticos con poca representación en el Congreso de la República verían las consecuencias de los Actos Legislativos 01 de 2009 y 01 de 2013. A partir del primero los partidos y movimientos políticos para adquirir o conservar su personería jurídica deben obtener el 3\% de los votos emitidos válidamente para el Senado de la República o Cámara de Representantes en todo el territorio nacional, lo que equivale a poco más de 450.000 votos $^{1}$. Se decía que el MIRA, la Alianza Verde y el PIN estaban en peligro de desaparecer formalmente. La única reforma constitucional de 2013, por su parte eliminó la circunscripción especial

1 Se recuerda que para las elecciones legislativas de 2010 se decidió aplicar ultractivamente la disposición que se dejaba atrás ( $2 \%$ de la votación nacional), según lo dispuesto en el Parágrafo Transitorio del artículo $2^{\circ}$ de la reforma constitucional. 
de minorías políticas, trasladando su curul a la circunscripción internacional. Al final, los resultados demostraron que esas advertencias resultaron excesivas.

Esta situación, en todo caso, revela que en materia electoral la condición de ser minoría política dentro de un cuerpo colegiado de elección popular (no en otro hay pluralidad) en Colombia se relaciona al número de votos obtenidos en la contienda electoral, lo que se ve reflejado en la asignación de las curules en el Congreso de la República, Asambleas Departamentales y Concejos.

A esta conclusión ya había llegado la Corte Constitucional en la Sentencia C-122 de 2011 y años atrás un sector minoritario dentro del Consejo de Estado, que fue derrotado por una tesis mayoritaria que identificó el ser minoría política con ejercer la oposición política.

Este interés constitucional en las minorías políticas y la oposición política, se debe a la conformación multi-ideológica de la Asamblea Constituyente de 1991, en la que se hicieron cambios al vetusto sistema democrático colombiano. Entre ellos se resalta el reconocimiento de derechos para los partidos que no participaran del gobierno y para las minorías políticas, en su artículo 112. Esta consagración es relevante en cuanto a que se reconoce en la carta política la existencia e importancia de alternativas políticas diferentes a las presentadas por los partidos tradicionales, y la posibilidad de practicar la oposición política -consagrado a partir del Acto Legislativo 1 de 2003 (Art. $5^{\circ}$ )- o estar al margen del Gobierno.

El artículo 112 es el único del Capítulo 3 denominado "Del estatuto de la oposición" del Título IV de la Constitución -"De la participación democrática y de los partidos políticos" -, y en 2003 fue reformado para afinar los derechos de quienes ejercen la oposición política.

Su inciso segundo ha sido desarrollado legislativamente así: el artículo 40 de la Ley $5^{a}$ de $1992^{2}$ establece que las minorías políticas tienen derecho a ocupar la primera vicepresidencia de las mesas directivas del Senado de la República y la Cámara de Representantes "a través del partido o movimiento mayoritario entre las minorías". Su parágrafo dispone que en tratándose de las comisiones, los presidentes y vicepresidentes no podrán ser del mismo partido o movimiento político.

2 Deroga al artículo 18 Inc. $4^{\circ}$ de la Ley 17 de 1970 que otorgaba alguna de las vicepresidencias a la "minoría más numerosa en cada Cámara". 
El artículo 28 de la Ley 136 de 1994, por su parte, establecía el mismo derecho en el caso de las mesas directivas de los Concejos, "a través del partido o movimiento político mayoritario entre las minorías" .

Pero, si bien la Constitución y la Ley hablan de minoría política, no se dice en ese contexto de democracia representativa ¿qué identifica a un partido o movimiento político como minoritario?, y también hace falta saber ¿cuáles son sus características?

\section{HIPÓTESIS DE TRABAJO}

A la anterior pregunta de reflexión se dio respuesta, en esos pronunciamientos del Tribunal Supremo de lo Contencioso-Administrativo surgidos a cuenta de sendas demandas de nulidad electoral interpuestas contra elecciones de las mesas directivas de las corporaciones colegiadas de elección popular en cargos previstos para las minorías políticas en el desarrollo legislativo del artículo 112 constitucional. La tesis mayoritaria del Consejo de Estado en cerca de seis años terminó por igualar el concepto de "minoría política" con el de "oposición política" al interpretar exegéticamente -utilizando las técnicas semántica e histórica-el confuso artículo 112 superior.

Las resultas de este debate fueron puestas en conocimiento de la Corte Constitucional mediante una demanda de inconstitucionalidad contra una de las normas que le otorgaban a los partidos minoritarios un cargo en la mesa directiva de las cámaras del Congreso de la República.

El cancerbero constitucional demuestra en la C-122 de 2011 cómo desde una interpretación exegética, primero, y sistemática, después, el ser "minoría política" es una cuestión de número y no de orientación política frente al gobierno de turno, lo que es consecuencia, en el entender de la Corte, de adoptarse en la Constitución de 1991 un régimen de gobierno presidencialista y un sistema electoral proporcional. Desde luego, esta controversia hermenéutica enriquece los parámetros de la interpretación constitucional, y es un duro ejemplo para los jueces ordinarios sobre cómo no deben ejercerla de manera exclusiva desde la exégesis.

Este escrito se justifica también en cuanto ayuda a caracterizar un elemento importante de la democracia representativa, como lo es el concepto de minoría política.

3 El artículo 22 de la Ley 1551 de 2012 sustituye esta disposición a reconocer este derecho a los partidos que se declaren en oposición al Alcalde. Ahora en las Mesas Directivas de los Concejos debe haber representación tanto de las minorías políticas como de la oposición política. Se cita la norma primigenia por ella estar vigente al momento en que se profirieron las sentencias que luego se explicarán. 


\section{METODOLOGÍA DE ANÁlisis DEL PROBLEMA PROPUESTO}

Para el análisis de las sentencias se utiliza el análisis dinámico del precedente judicial del que habla López Medina (2009), y en tal virtud se construye una línea jurisprudencial, para determinar los elementos del concepto de minoría política en la democracia representativa en la Constitución colombiana de $1991^{4}$. Lo anterior es posible ya que se cuenta con un número importante de sentencias para analizar y a que es posible reducir sus discusiones a un mismo problema jurídico.

En efecto la Sección Quinta del Consejo de Estado tuvo la oportunidad de pronunciarse en seis sentencias sobre el contenido del artículo 112 superior. Debe advertirse que aquellas se iniciaron por demandas promovidas contra las elecciones de las mesas directivas de los Concejos, y las plenarias y comisiones permanentes del Congreso de la República en las que se acusaba a quien fue electo como primer vicepresidente de no pertenecer al grupo mayoritario de las minorías.

Y por encima de los hechos accidentales de estas sentencias -por ejemplo, la corporación a la que pertenecía el demandado y otros cargos de nulidad que no se relacionan con el tema aquí se aborda-, se ha edificado como problema jurídico de la línea el responder si ¿el derecho de los partidos y movimientos políticos minoritarios a participar en la Mesa Directiva debe regularse a través de una Ley Estatutaria?, dentro del escenario constitucional del "Concepto de minoría política en la democracia representativa en Colombia”.

Uno y otro se relacionan en cuanto en estas decisiones el Consejo de Estado equipara los conceptos de minoría política y oposición política, termina por inaplicar por inconstitucionalidad los artículos 40 de la Ley

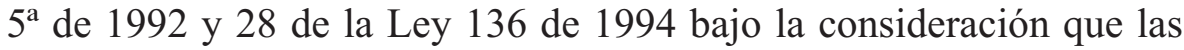
afectaba un vicio de inconstitucionlidad debido a que su contenido debe ser regulado por una ley estatutaria, y por el contrario hacían parte de una ley orgánica y ordinaria, respectivamente.

Ahora si bien la Corte Constitucional en la Sentencia C-122 de 2011 analiza la constitucionalidad del Parágrafo del artículo 40 de la Ley $5^{\text {a }}$ de

4 Este es el límite del objeto de investigación de este escrito. No se habla aquí de un concepto material o sociológico de minoría política que se pudiera edificar para la democracia participativa, bajo el entendido que la práctica partidista y electoral no es la única forma de hacer política; tampoco se habla del concepto de minoría política de la circunscripción especial que eliminó el Acto Legislativo 01 de 2013. 
1992, norma que es orgánica y no estatutaria, al concluir que el artículo 112 regula dos materias diferentes, una los derechos de la oposición y la naturaleza de las leyes que lo deben regular (incisos $1^{\circ}$ y $3^{\circ}$ ), y la otra el derecho de los partidos y movimientos minoritarios con personería jurídica de tener asiento en las mesas directivas de los cuerpos colegiados de elección popular (inciso $2^{\circ}$ ), se puede sostener que el desarrollo legislativo de este derecho puede darse mediante leyes ordinarias.

A continuación se grafica esta línea jurisprudencial.

Tabla 1. Línea jurisprudencial del Consejo de Estado sobre la necesidad de regular la representación política de las minorías en una ley estatutaria.

\begin{tabular}{|c|c|c|c|}
\hline & \multicolumn{2}{|c|}{$\begin{array}{l}\text { ¿El derecho de los partidos y movimientos políticos } \\
\text { minoritarios a participar en la Mesa Directiva debe regularse a } \\
\text { través de una Ley Estatutaria? }\end{array}$} & \\
\hline $\begin{array}{c}\text { Sí } \\
\text { En tanto es un } \\
\text { derecho de la } \\
\text { oposición } \\
\text { política debe } \\
\text { regularse a } \\
\text { través de una } \\
\text { ley estatutaria } \\
\text { según los arts. } \\
122 \text { Inc. } 3^{\circ} \text { y } \\
152, \text { Lit. c) }\end{array}$ & $\begin{array}{c}\text { X } \\
10 \text { Mar. 2005, M. Hernández } \\
\text { (3540). C.E. Sec. 5a } \\
\text { X } \\
\text { 12 May. 2005, R. Chavarro } \\
\text { (3702). C.E. Sec. 5 } \\
\text { X } \\
\text { 19 Feb. 2009, M. Torres } \\
\text { (2008-00266). C.E. Sec. 5a } \\
\text { X } \\
\text { 28 Ago. 2009, M. Torres } \\
\text { (2008-00024). C.E. Sec. 5a } \\
\text { X } \\
\text { Salvamento } \quad 30 \text { Nov. } 2 \\
\text { M. Torres } \quad(2009-000\end{array}$ & $\begin{array}{l}\text { X } \\
09 \text { Oct. 2003, D. Quiñonez } \\
\text { (3141). C.E. Sec. 5a } \\
\text { X } \\
\text { Aclaraciones (2) de Voto: } \\
\text { F. Jiménez y S. Buitrago } \\
\text { X } \\
\text { Salvamentos (2) de Voto } \\
\text { Jiménez y S. Buitrago } \\
\\
\text { S. Buitrago } \\
\text { C.E. Sec. 5a } \\
\quad X \\
\text { C-122-2011, J.C. Henao } \\
\text { C. Const. }\end{array}$ & $\begin{array}{c}\text { No } \\
\text { Minoría política no es } \\
\text { equivalente a oposición } \\
\text { política, por tanto los } \\
\text { derechos de las minorías } \\
\text { políticas no deben } \\
\text { regularse vía ley } \\
\text { estatutaria. }\end{array}$ \\
\hline
\end{tabular}


Para los fines expositivos, el documento se divide en tres partes. En la primera se expone un análisis de las jurisprudencias del Consejo de Estado resaltando sus tesis fundadas tanto en una interpretación "histórica" como "lógica" del artículo 112 superior. Enseguida se detallará la sentencia C-122 de 2011 con sus interpretaciones histórica, lingüística y sistemática del artículo 112; finalmente se recabarán unas conclusiones que detallan el concepto anunciado.

\section{EL CONSEJO DE ESTADO ENCERRADO EN SU EXÉGESIS}

\subsection{Una temprana jurisprudencia}

Con la Sentencia del 9 de octubre de 2003 empieza a fondo las discusiones en torno a quién se debe considerar partido o movimiento minoritario para que pueda hacer valer el derecho de ocupar un puesto en la mesa directiva de un cuerpo colegiado. En esta decisión no se cuestiona la constitucionalidad del artículo 28 de la Ley 136 de 1994, por lo que implícitamente acepta que es un tema que no debe ser regulado por ley estatutaria, pero se deja en claro que la minoría política se establece "con el número de curules que obtuvo un partido o movimiento político en determinada contienda electoral." En el caso particular, no prosperó la demanda debido a que el representante del único partido minoritario ocupaba la Presidencia del Concejo. Por no agotar en profundidad todo el problema jurídico se decide ubicarla dentro de la línea jurisprudencial más al centro, respecto de las posteriores sentencias que sí lo abordan.

\subsection{La argumentación lógico-exegética}

Estas primeras pinceladas sobre lo que es una minoría política empiezan a ser dejadas atrás por la jurisprudencia del Consejo de Estado. Esta modificación en su línea jurisprudencial empieza con la Sentencia del 10 de marzo de 2005, que es bien particular: es la primera vez en que el Consejo de Estado sostiene que el derecho de participar en las mesas directivas de las corporaciones colegiadas debe regularse por una Ley estatutaria, lo que supone de nuevo de manera tácita equiparar oposición y minoría política, pero a su vez concreta el criterio numérico para determinar quién adquiere esa segunda condición.

Funda esta nueva postura la lectura del inciso $3^{\circ}$ del artículo 112 y el numeral c) del artículo 152 de la Constitución. El Consejo de Estado entiende el artículo 112 como una unidad indivisible: todos sus incisos se refieren a una misma materia, que es el estatuto de la oposición. 
En lo que sí se esfuerza es en demostrar que regular el derecho a participar de la oposición/minoría política en las mesas directivas de los cuerpos colegiados en una ley ordinaria, como lo es la Ley 136 de 1994, no es un simple vicio de forma que caduca al año de expedirse la ley-esto conforme al art. 242 CPC-sino una infracción material a la Constitución pues fue expedido sin competencia, ya que su aprobación exige la mayoría absoluta del Congreso, y con elusión del control de constitucionalidad previo por parte de la Corte Constitucional, lo que se obvió en el caso del artículo 28 de la Ley 136 de 1994. Así lo inaplica en ejercicio de la excepción de inconstitucionalidad.

Ahora al tener que desatar las demandas, el Consejo de Estado encuentra que el único referente normativo frente al cual puede confrontar el acto acusado es el artículo 112 superior y avalaba la elección impugnaba pues no importa si el elegido representa o no al partido mayoritario de las minorías políticas. Y para determinar quién es mayoría sigue el parámetro de la sentencia del 9 de septiembre de 2003. El grupo mayoritario es aquel que conquiste el mayor número de curules, y minoritarios todos los demás. Ello por dos argumentos: (i) son los partidos y movimientos políticos quienes conquistan los cargos públicos de elección, y no los candidatos individualmente considerados; (ii) el número total de votos obtenidos por cada vertiente política sólo es factor para repartir las curules entre ellas, pero en las decisiones corporativas cada miembro tiene un voto sin importar el número de sufragios con que salió elegido.

¿Por qué si el Consejo de Estado pareciera tener claro que el ser mayoría o minoría se determina con el número de curules obtenidas, establece que la representación de las minorías en las mesas directivas es un asunto del Estatuto de la oposición, el que se aplica para los partidos y movimientos que asuman una postura política contraria al Gobierno? Es una total contradicción, inexplicable en la sentencia.

Aquella postura del Consejo de Estado es reiterada en las Sentencias del 12 de mayo de 2005 y del 19 de febrero de 2009. En esta última aparece un nuevo argumento en su respaldo, habida cuenta de la presentación de dos aclaraciones de voto. Se acude a la regla hermenéutica prevista en el artículo 28 del Código Civil según la cual "cuando el sentido de la ley sea claro, no se desatenderá su tenor literal a pretexto de consultar su espíritu...". Basta observar el tenor literal de los artículos 112 y 152, dice el Consejo de Estado, para comprender claramente que el artículo 112 regula una misma materia. 
Esta regla hermenéutica tuvo considerable éxito durante, y se explica, desde el clasicismo jurídico colombiano, la más temprana y perdurable experiencia de la cultura jurídica en el país. En particular, el artículo 28 del Código Civil rinde culto a la obra del legislador, la cual se considera perfecta, completa, totalizante, sin imperfectos o vacíos. Sin embargo, esta fe ciega en el texto de la norma escrita requería muchas veces el abuso de argumentos de autoridad y la creación de ficciones (Gómez Serrano, 2008), como lo es precisamente la equiparación a la que llega el Consejo de Estado.

Las aclaraciones presentadas en esa sentencia por los Consejeros Filemón Jiménez Ochoa y Susana Buitrago Valencia muestran unas deficiencias de la lectura del artículo 112 constitucional por parte de la posición mayoritaria del Consejo de Estado. Para ellos, por el contrario, este regula dos materias totalmente diferentes e independientes: uno (i) los derechos de los partidos de oposición, que se deben regular a través del Estatuto de la Oposición, lo que desde luego corresponde a una ley estatutaria, y otro (ii) los derechos de los partidos minoritarios a participar en las mesas directivas, que se puede desarrollar mediante una ley ordinaria.

Esta distinción es:

posible en la medida en que oposición y minoría no son, como lo da a entender el fallo, sinónimos, menos en una democracia pluripartidista como la nuestra; a lo sumo en una bipartidista en donde es claro que el partido que no obtiene el poder además de ser la minoría es el partido de oposición.

Así la referencia del inciso $3^{\circ}$ del artículo 112 es al primer inciso ibídem y no al segundo. Aquí por primera vez se hace referencia a la Asamblea Nacional Constituyente aunque en favor de la postura contraria a la posición mayoritaria de la Sección Quinta. En todo caso, esta referencia a la Asamblea Nacional Constituyente abre el camino para la segunda argumentación con que el Consejo de Estado iguala a minoría con oposición.

\subsection{La argumentación histórico-exegética}

El debate dentro de la Sección Quinta se reanuda meses después en la Sentencia del 28 de agosto de 2009, y se salda con la intervención de un conjuez ${ }^{5}$ en favor del hilo argumentativo ya expuesto: la participación de

5 Las anteriores aclaraciones de voto se presentan ahora como salvamentos. 
los partidos y movimientos minoritarios en las mesas directivas de las corporaciones de elección popular corresponde al estatuto de oposición, que debe ser desarrollado mediante una ley estatutaria, por lo que inaplica esta vez el artículo 40 de la Ley $5^{\text {a }}$ de 1992, puesto que se demandaba en dicha ocasión en la elección de la Mesa Directiva de la Comisión Segunda del Senado, por ser aquella una ley orgánica y no una estatutaria.

En esta sentencia la argumentación de la Sección Quinta cita discusiones de la Asamblea Nacional Constituyente de las que resalta tres aspectos: (i) la necesidad de reconocer garantías a quien no quiera participar del gobierno y posibilitar una alternativa política "distinta", (ii) la utilidad de reconocer derechos a la oposición, además de la participación de los partidos y movimientos minoritarios en las mesas directivas de los cuerpos colegiados, de acuerdo con su representación en ellos -esto de manera clara va en contra de lo que se termina sosteniendo-, (iii) el desacuerdo sobre la redacción del texto original del artículo 112 puesto que la voz "partidos y movimientos políticos que no participen en el Gobierno" pareciera incluir tanto los de la oposición como los que sin estar con el gobierno tampoco están en la oposición. A juicio de un sector que evidentemente fue derrotado, debía dejarse claro que esos derechos eran para la oposición.

Con lo anterior concluye diáfanamente el Consejo de Estado que "cuando el artículo 112 trata sobre el derecho de los partidos y movimientos políticos minoritarios con personería jurídica a participar en las mesas directivas de los cuerpos colegiados, alude precisamente a aquellos que se declaren en oposición".

Enseguida para reforzar su tesis, señala que la reforma constitucional realizada mediante el Acto Legislativo 01 de 2003 modifica el artículo 112, se hizo para fortalecer los derechos de la oposición, puesto que, según debates realizados en su aprobación, la redacción original de su inciso primero podría generar "que movimientos políticos que tradicionalmente han sido gobiernistas, o que pueden estar en un momento determinado a favor del Gobierno para beneficiarse de los derechos de la oposición y arrebatárselos a quienes verdaderamente son oposición". De ahí en adelante la sentencia hace referencia a las "minorías políticas en oposición". Es raro pero escapa a la imaginación del Consejo de Estado que un Presidente de la República cuente algún día con un Congreso mayoritariamente en su contra. 
Finalmente en esta decisión se declaran nulas las elecciones impugnadas habida cuenta que en la mesa directiva de esta comisión no había representación de los partidos de oposición, lo que exige el artículo 112 de la Constitución.

Un caso similar tuvo que ser decidido por la Sección Quinta en la Sentencia del 30 de noviembre de 2010. En dicha ocasión la ponencia correspondió a una de las consejeras que tradicionalmente habían salvado el voto.

Contrario a lo que podía pensarse, ella no replicó los argumentos presentados en sus aclaraciones y salvamentos de voto. La parte motiva comienza con la cita a la Sentencia del 24 de abril de 1987 también de la Sección Quinta del Consejo de Estado, en la que se interpreta el artículo 17 del Acto Legislativo 01 de 1968. Ella expresa claramente que minorías en el contexto político colombiano son los partidos o movimientos inferiores a los dos partidos tradicionales que constituyen las mayorías políticas en el país. En aquel caso también similar al de 2010, los cargos de la mesa directiva del Senado y Cámara de Representantes resultaron ocupados por miembros del Partido Liberal y Conservador, y no por los del Nuevo Liberalismo, la fuerza política más numerosa entre las minorías.

Luego se contrasta esta interpretación con la reforma de 2003 a la Constitución de 1991 para decir que ella había reducido el reconocimiento de los derechos de oposición a los partidos y movimientos con personería jurídica que se declaren en oposición al gobierno. Enseguida recopila los diferentes pronunciamientos sobre la interpretación del artículo 112 por parte del Consejo de Estado y achaca el origen de las posiciones antinómicas a la falta de regulación legal de la participación de la oposición y de las minorías.

Sin embargo, la argumentación de esta sentencia no se amilana ante el precedente horizontal y presenta razones por las que ha de seguirse un nuevo rumbo: (i) en rigor etimológico minoría no significa oposición y se respalda en definiciones del diccionario de la Real Academia Española. Se presenta pues una conclusión distinta con un argumento semántico-exegético; (ii) y la condición sine qua non para que un partido puede calificar dentro de la voz "contradictores del gobierno" es que sea de oposición, "con indiferencia de si el partido o movimiento político es mayoría o es minoría respecto de su representación en el cuerpo colegiado"; (iii) al no existir aún el estatuto de la oposición no se cuenta 
con un "procedimiento" para "la participación de estos partidos y movimientos políticos contradictores del gobierno en la integración de las mesas directivas de los cuerpos colegiados", por lo que es imposible que se estructure un vicio por violación del artículo 112 superior, debido a la no elección dentro de la mesa directiva de la Comisión Segunda del Senado de la República de un miembro de un partido de oposición.

La ponencia es tanto ingeniosa como sutil: evita pronunciarse sobre la inconstitucionalidad del parágrafo del artículo 40 de la Ley $5^{\text {a }}$ de 1992, y en cuanto a que se discute sobre la mesa directiva de una comisión y no de la plenaria del Senado expone que para determinar en cabeza de quien está el derecho previsto en el inciso $2^{\circ}$ del artículo 112 debe estudiarse la composición de la comisión puesto que la minoría se establece "según su representación" en ella.

En el caso particular, resulta que tanto el partido de quien resultó electo como el del otro candidato que perdió la elección ${ }^{6}$ tenían el mismo número de curules - una menos que el mayoritario- por lo que concluye la Sección Quinta que no había violación del artículo 112. De esta manera la ponente logra un acuerdo mayoritario en la Sección Quinta lo que posibilita un cambio en el sentido de la parte resolutiva, pues no se declara nula la elección.

Es claro que en esta sentencia no son sinónimos minoría y oposición política.

Pragmatismo por encima de rigor conceptual podría ser el epígrafe de esta resolución judicial. ¡Casi una década de jurisprudencia y no se cuenta con claridad en la materia! Estos pronunciamientos en exceso abstractos hacen de la seguridad jurídica una quimera.

Se decide ubicar esta sentencia en el centro de la línea jurisprudencial debido a que intencionalmente no agota todo lo planteado en el problema jurídico.

$\mathrm{Y}$ en referencia al elemento hermenéutico, debe recordarse que el estudio del proceso de creación normativo es una tecnificación del modo de pensar el Derecho por parte de la Escuela Histórica del Derecho. Ella "considera que el derecho era producto del espíritu -de la voluntad-del pueblo" (Bastida, 2001, p. 45) o Volksgeist, forjado a lo largo de la historia y no el resultado de un acuerdo general de voluntades.

6 Sólo hubo dos. 
A fin de desentrañar este espíritu para el intérprete es precisa la "'reconstrucción de la idea expresada en la ley, en cuanto es cognoscible a partir de la ley'... Para "poder saber la idea de la ley' tienen que tenerse en cuenta las circunstancias históricas de su génesis" (Larenz, 2010, pág. 32).

También interpretar la Constitución desde esta técnica tiene sus riesgos. La realidad sin duda puede dejar atrás a la ley, y nada impide que también informe a la norma de normas, y lo pensado por el Constituyente puede resultar inadecuado años después para la sociedad a la que se dirige. Así se ha dicho que el texto constitucional se independiza de sus redactores para desenvolverse en una sociedad que evoluciona, debiendo actualizarse como necesidad histórica, por lo que tras su creación pasa a ser “un instrumento vivo, orgánico y cambiante” (Sagües, 2007, pág. 7).

Y pretender encontrar la voluntad del constituyente y el legislador, a juicio de la Escuela de la Libre Investigación Científica “deja un campo abierto al intérprete para incluir en él ideas propias, cuyo resultado no es sino un proceso permeado de subjetividad"(Bernuz, 2006, pág. 198).

\section{LA CORTE CONSTITUCIONAL: COMBINACIÓN DE MÉTODOS DE INTERPRETACIÓN}

A esta altura del debate en el Consejo de Estado, una ciudadana ejerce la acción pública de inconstitucionalidad ante la Corte Constitucional contra el parágrafo del artículo 40 de la Ley $5^{\text {a }}$ de 1992 , y presenta de lleno las conclusiones a las que llegó el Consejo de Estado en la Sentencia del 28 de agosto de 2009, como cargos de inconstitucionalidad.

Aunque no es un caso de control constitucional sobre interpretación de normas, la Corte toma muy en cuenta los considerandos de la Sentencia del 29 de agosto de 2009 del Consejo de Estado. Es más, edifica a partir de ella, en parte como una respuesta, la parte motiva de su fallo. Como un buen maestro el ponente presenta paso a paso, en una argumentación ascendente y articulada, como desde una interpretación histórica, lingüística o semántica y sistemática del artículo 112 se obtiene una conclusión diferente a la que llegó la Sección Quinta.

\subsection{Interpretación histórica}

Para ejercer la interpretación histórica la Corte toma dos fuentes: un libro editado por la Presidencia de la República que recopila las 
discusiones de la Asamblea Nacional Constituyente, correspondientes a los días 10 y 15 de mayo, 13 y 18 de junio de 1991, y que no se encuentran en las Gacetas Constitucionales ${ }^{7}$. Y dos libros: uno publicado por el constituyente Alfonso Palacio Rudas (El Congreso en la Constitución de 1991) y "La Constitución que no fue" de Manuel José Cepeda Espinosa. De las discusiones en la Comisión Primera de la Asamblea Nacional Constituyente destaca que un representante del conservadurismo planteó la necesidad de establecer un estatuto de la oposición limitado a los partidos tradicionales "como una fórmula de establecer la paridad" y que en el proyecto inicial del artículo 112 se reconocía el derecho de su inciso segundo a las "minorías electorales" lo que se cambió después.

Y para entender la independiente regulación de derechos de la oposición y de las minorías políticas resalta que uno de los constituyentes dijo:

"además una consagración que lamentablemente se olvida a ratos y aquí mismo fue olvidada en sus comienzos, que es que los partidos y movimientos minoritarios tendrán derecho a participar en las mesas directivas de los cuerpos colegiados, de acuerdo con su representación en ellos; me parece que la garantía de las minorías es otra norma muy importante de ser aprobada..."

Respecto de los libros, se evidencia que no es clara la equivalencia entre ser oposición y ser minoría. En esta interpretación concluye la Corte que

la interpretación histórica realizada por la Sección Quinta del Consejo de Estado en la excepción de inconstitucionalidad de 28 de agosto de 2009 , no es acertada... una vez analizados los debates en la constituyente se puede concluir sin lugar a dudas que siempre se dio un tratamiento separado a los derechos de los partidos y movimientos que no participaran en el gobierno -no se les llamó en esta primera redacción partidos de oposición- $\mathrm{y}$ a la participación de los partidos minoritarios en las mesas directivas del inciso segundo. Finalmente el inciso tercero referente a que una ley estatutaria regularía íntegramente la materia, se aprobó independiente de los incisos anteriores.

En la reforma constitucional realizada en 2003 se dejó intacto el inciso tercero del artículo 112 constitucional. (Ver cuadro al final del documento o Anexo I).

7 Estas tienen proyectos de reformas de la Constitución, propuestas de particulares, informes de debates de comisión y ponencia para aprobación de la Asamblea Nacional constituyente, pero no actas de las discusiones. 


\subsection{Interpretación lingüística o semántica}

Es característica de esta técnica hermenéutica que se ponga atención a las palabras con las que se expresa la voluntad de quien profiere la norma jurídica, por lo que es útil acudir a las definiciones que dan las autoridades del idioma a fin de superar la vaguedad o ambigüedad de los términos utilizados. Con su sentido natural y obvio, el intérprete debe respetarlo.

Comienza por interpretar el concepto de "minoritario" a través de la definición traída por el diccionario de la Real Academia Española destacando sus dos acepciones reseñadas en la anterior gráfica. Enseguida plantea que en cuanto al lenguaje político este varía según: (i) el régimen político adoptado y las relaciones entre el Gobierno y el Congreso; (ii) el sistema electoral que se escogido; (iii) y ciertas garantías a grupos pequeños a quienes se les otorga escaños permanentes con circunscripciones especiales.

Para explicar el primero acude al derecho comparado y pone de ejemplo que en los regímenes parlamentarios en los que existen dos grandes partidos que se alteran el poder; la minoría que no gana las elecciones y ni participa ejerce de oposición. En los otros, en donde son necesarias las coaliciones para conformar el gobierno son minoría "todos aquellos partidos que no han obtenido la mayoría de curules en el parlamento", que pueden ser parte o no de la coalición de gobierno, o plantean como neutrales.

Tratándose de regímenes presidencialistas como el caso colombiano minoría puede entenderse que son "los partidos que no se corresponden con el partido político del presidente", o "los partidos políticos que han obtenido menores escaños en el Congreso". La Corte pone de manifiesto las posibilidades de relación entre el Presidente y el poder legislativo en un régimen presidencialista: (i) el partido mayoritario en el Congreso de la República no puede ser el del Presidente, y (ii) diversidad de minorías: unas de oposición, otras neutrales y otras con participación en el Gobierno. Resalta de estas últimas que "no pierden tal condición por esta decisión "porque siguen teniendo un menor número de curules en el Congreso y en segundo término porque no pierde la posibilidad de romper en cualquier momento la coalición y empezar a hacer oposición a su anterior aliado".

Ahora tratándose de un sistema electoral puro sólo se posibilita la existencia de una minoría, mientras que el proporcional se aumenta la posibilidad de que existan varios. 
Tras esto se pregunta la Corte, ¿Qué tenemos en Colombia? Un régimen presidencialista con un sistema electoral proporcional, es su respuesta. Aquí surgen las siguientes posibilidades: a) "que exista una correspondencia entre el partido político que gobierna y el partido político mayoritario en el Congreso", b) que "no exista correspondencia entre el partido de gobierno y el partido mayoritario en el Congreso"; c) por tratarse de un sistema bicameral, "puede ocurrir que una Cámara del Congreso se corresponda con el partido de gobierno y la otra no"; d) a la manera de un régimen parlamentario, puede "darse un gobierno de unidad nacional en donde se dé representación en el gobierno a todos los partidos políticos y no exista una oposición declarada de ningún partido en el Congreso".

De esta interpretación lingüística concluye la Corte que "no se puede hacer la correspondencia entre 'partido y movimiento político minoritario' con 'partido y movimiento político de oposición'".

Para comprender las disímiles conclusiones del Consejo de Estado y de la Corte Constitucional respecto de las normas jurídicas que regulan el derecho de las minorías políticas a ocupar cargos en las mesas directivas de las corporaciones colegiadas de elección popular, desde esta técnica cabe recabar en las diferencias entre el signo, el significado y el sentido de las palabras. El signo es el objeto que la palabra sustituye o representa, y cobija a todos los que tienen unas características generales. El significado es el contenido del signo, y lo condiciona el contexto que lo rodea. Finalmente, el sentido es el entendimiento que se hace el lector de una proposición.

Y cuando la posición mayoritaria del Consejo de Estado señala que son equivalentes minoría y oposición política se tiene que en su comprensión esos términos diferentes representan un mismo objeto, cuyo significado se determina por el artículo 112 superior. Por el contrario, para la Corte Constitucional minoría política y oposición política representan signos independientes entre sí, y como se verá enseguida, el contexto al que acude para determinar especialmente el significado de "minoría política" es mucho más amplio al del artículo 112.

\subsection{Interpretación sistemática}

Comienza la Corte recordando que para la demandante al denominarse "Del Estatuto de la Oposición", el capítulo dentro del cual se encuentra el artículo 112, y al aludir el inciso tercero de este, indistintamente a los 
dos primeros incisos, la forma de entender partido minoritario, es que sea de la oposición, mientras que para uno de los intervinientes en el proceso constitucional no hay unidad normativa entre el inciso primero y segundo del artículo 112, pues la titulación de la Constitución, ha dicho la Corte desde la Sentencia T-002 de 1992, es enunciativa y no vinculante.

La Corte resalta estas contradictorias posturas para plantear la necesidad de conjugar tanto la interpretación histórica y lingüística, para encontrar que: a) con la histórica se comprueba que "los incisos 1 y 2 del artículo 112 de la CPC son separables y se pueden interpretar independientemente", no existiendo entonces unidad normativa en él; b) el inciso 3 del artículo 112 debe interpretarse junto con el artículo 152 literal c), por lo que la relación directa del mentado inciso 3, es con el primero y no con el segundo. Quiere decir la Corte, que lo que debe regularse en una ley estatutaria es el Estatuto de la Oposición, y no la representación de los partidos minoritarios en las mesas directivas de los organismos colegiados de elección popular.

Luego la Corte expresa que de seguir a pie juntillas la interpretación del Consejo de Estado se podría llegar a dos absurdos: se imposibilitaría la renovación de las mesas directivas, tal y como lo exige el artículo $147^{8}$, en caso que los miembros de la oposición sean muy pocos; (ii) un partido minoritario sólo tendría derecho a participar en las mesas directivas de las corporaciones colegiadas de elección popular si se declara en oposición al Gobierno. No tendría así opción de decidir, lo que niega la democracia.

Finalmente, concluye la Corte que:

desde una interpretación sistemática del inciso segundo del artículo 112, y teniendo en cuenta las posibles consecuencias que generaría la interpretación de la demandante, no se puede inferir que el derecho de participación en las mesas directivas del Congreso se dé únicamente para los partidos y movimientos políticos de oposición. Lo anterior porque como se analizó el término de 'minoría política' es mucho más amplio que el de 'minoría oposición', interpretación que se corresponde con el artículo 1 sobre democracia pluralista y participativa, con el

8 Establece que "Las mesas directivas de las cámaras y de sus comisiones permanentes serán renovadas cada año, para la legislatura que se inicia el 20 de julio, y ninguno de sus miembros podrá ser reelegido dentro del mismo cuatrienio constitucional". 
artículo 40 sobre la posibilidad de todo ciudadano de participar en la conformación, ejercicio y control del poder político, con el artículo 135 que establece que son facultades de cada Cámara elegir a sus directivas y con las normas constitucionales referentes a la representación proporcional en el Congreso.

Lo anterior implica que la regulación de los derechos de las minorías a participar de las mesas directivas no debe regularse por Ley estatutaria, por lo que el artículo 28 de la Ley 136 de 1994 durante el tiempo en que estuvo vigente fue constitucional. En el caso de la disposición acusada, además de lo anterior se respalda la decisión en virtud del artículo 151 de la Constitución que señala que la ley que reglamente la labor del Congreso es orgánica. (Ver al final del documento la gráfica que representa los resultados de las diferentes interpretaciones que propone la Corte Constitucional o Anexo II).

\subsection{La buena exégesis para interpretar la Constitución}

¿Cómo podría defenderse una buena exégesis de la Constitución, después de mostrar los errores a que con ella llegó el Consejo de Estado y las desavenencias que ella puede derivar al interpretar de esa manera un texto tan abierto e indeterminado?

Sin duda es difícil. Si a lo largo de este documento se han mostrado los riesgos de interpretar un texto constitucional a través de los cánones de la exégesis, sería de esperarse que la Corte Constitucional se desligara de ella. Por el contrario, ella la utiliza y llega a una conclusión contraria.

Sostiene el profesor Bohórquez (2013) que toda herramienta hermenéutica "mal empleada conducirá a resultados absurdos". El autor de este escrito es consciente de lo difícil que resultaría establecer una especie de "presupuestos hermenéuticos" para interpretar la Constitución desde la exégesis. Cree eso sí, a partir de la práctica mostrada en la Sentencia C 211- de 2011 poder plantear la actitud que un antiformalista debe asumir si decide utilizarla.

Si imaginamos la hermenéutica como el camino que lleva al entendimiento del Derecho, la exégesis se plantea como una piedra enorme que no deja mirar al caminante lo que hay después de ella. Si este es un formalista, se contentará y hará en ella hasta su hogar. Por el contrario, el buen caminante la toma como un punto importante pero no definitivo de dicho quehacer; se aupará en ella para llegar a su destino. 
La clave en la sentencia de la Corte Constitucional es combinar las técnicas de la exégesis, sumarle un análisis de derecho comparado y verificar las consecuencias que traería lo que de ellas resulte en el sistema jurídico del que hace parte la norma interpretada.

\section{CONCLUSIÓN}

La decisión de la Corte Constitucional hace que sean aplicables las consideraciones expuestas por el Consejo de Estado en las Sentencias del 09 de octubre 2003 y 10 de marzo de 2005, en relación con los criterios para determinar quién es minoría. Juntas permiten identificar los siguientes elementos de este concepto de minoría política que hacen que sea:

- Cuantitativo. Las curules obtenidas en cada corporación colegiada de elección popular, así como en las comisiones en las que se subdivide, que representan el número de sufragios conseguidos en cada contienda electoral es lo que determina quién es el partido mayoritario y minoritario. Partido o movimiento minoritario es todo aquel que no obtenga el mayor número de curules. Si hay dos partidos con igual número de escaños y superior a todos los demás, ambos serán mayorías; y puede suceder lo mismo con los partidos minoritarios. Entre partidos con el mismo número de curules no puede deprecarse mayoría de uno u otro según el número de votos, debido a que para la toma de decisiones aquellos no tienen trascendencia. Así entonces, minoría política es minoría electoral.

- Subjetivo, ya que no importa la posición frente al gobierno. Es intrascendente para ser partido minoritario la posición política que se establezca frente al gobierno nacional, departamental o municipal. Haga parte o no del Gobierno, cada partido tiene una identidad propia que no se desdibuja por pactar unos propósitos mínimos con otras agrupaciones. Las posibles coaliciones o acuerdos que entorno a un programa logre un gobernante no niega los propósitos propios que tengan los partidos minoritarios, que justifican su existencia y hacen diverso al panorama político.

- Variable en el espacio y el tiempo. No se es partido o movimiento minoritario en todo el país y para siempre. Tal condición puede variar de municipio en municipio, y no corresponder siempre con la representación política en el Congreso de la República. Inclusive dentro de las mismas cámaras de este, pueden darse cambios. 
- Derivado de las elecciones. La condición de minoría política se adquiere después de ellas. Cada elección puede ser un nuevo comenzar, y quien en un tiempo fue mayoría política puede resultar siendo minoría.

\section{REFERENCIAS BIBLIOGRÁFICAS}

Bastida, X. (2001). El silencio del emperador: un ensayo sobre la unidad del ordenamiento jurídico. Bogotá: Universidad Nacional de Colombia.

Bernuz, M. (2006). Francois Gény y el Derecho: la lucha contra el método exegético. Bogotá: Universidad Externado de Colombia.

Bohórquez, A. (2013). "Como toda herramienta, subsunción y ponderación, cualquiera de ellas, mal empleada conducirá a resultados absurdos".2 de enero del2013,(@AntonioBohorqz)

Colombia - Ley 5a, 1992. "Por la cual se expide el Reglamento del Congreso; el Senado y la Cámara de Representantes". 17 de junio de 1992. "D.O." 40.483

Colombia - Ley 17, 1970. "Por la cual se dictan normas sobre las Comisiones del Congreso". 15 de diciembre de 1970. “D.O.”33.228.

Colombia - Ley 136, 1994. "Por la cual se dictan normas tendentes a modernizar la organización y el funcionamiento de los municipios". 02 de junio de 1994. "D.O." 41.377.

Colombia - Ley 1551, 2012. "Por la cual se dictan normas para modernizar la organización y el funcionamiento de los municipios". 06 de julio de 2012. “D.O.” 48.483.

Gómez Serrano, L. (2008). Las fuentes del derecho en el Ordenamiento Jurídico Colombiano, Temas Socio-Jurídicos, 55 (26), 13-38.

Larenz, K. (2010). Metodología de la Ciencia del Derecho. Barcelona: Ariel.

López Medina, D. (2009). El derecho de los jueces. Bogotá: Legis.

López Medina, D. (2011). Las fuentes del argumento. Bogotá: Legis. 
Sagües, N. (2003). Reflexiones sobre la Constitución viviente (Living Constitution). Revista Díkaion, (12), 1-18.

\section{SENTENCIAS ANALIZADAS}

Colombia - Corte Constitucional. Sala Plena. C-122 de 2011. (Juan Carlos Henao Pérez; $1^{\circ}$ de marzo de 2011).

Colombia - Consejo de Estado. Sala de lo Contencioso-Administrativo. Sección Quinta. Rad. 0650. (Miren De La Lombana De Magyaroff; 10 de Julio de 1992).

Colombia - Consejo de Estado. Sala de lo Contencioso-Administrativo. Sección Quinta. Rads. 1615-1618 (Miren De La Lombana De Magyaroff; 15 de Mayo de 1997).

Colombia - Consejo de Estado. Sala de lo Contencioso-Administrativo. Sección Quinta. Rad. 3141. (Darío Quiñones Pinilla; 09 de Octubre 2003).

Colombia - Consejo de Estado. Sala de lo Contencioso-Administrativo. Sección Quinta. Rad. 3540. (María Nohemí Hernández Pinzón; 10 de Marzo de 2005).

Colombia - Consejo de Estado. Sala de lo Contencioso-Administrativo. Sección Quinta. Rad. 3702. (Reinaldo Chavarro Buriticá; 12 de Mayo de 2005).

Colombia - Consejo de Estado. Sala de lo Contencioso-Administrativo. Sección Quinta. Rad. 2008-00266. (Mauricio Torres Cuervo; 19 de Febrero de 2009).

Colombia - Consejo de Estado. Sala de lo Contencioso-Administrativo. Sección Quinta. Rad. 2008-00024. (Mauricio Torres Cuervo; 28 de Agosto de 2009).

Colombia - Consejo de Estado. Sala de lo Contencioso-Administrativo. Sección Quinta. Rad. 2009-00039. (Susana Buitrago; 30 de Noviembre de 2010). 


\section{ANEXO I}

Tabla de comparación entre el texto original y la reforma de 2003 al artículo 112 CPC.

\begin{tabular}{|c|c|}
\hline \multicolumn{2}{|c|}{ Articulo 112} \\
\hline Texto Original & Acto Legislativo 1 de 2003 (Art. $5^{\circ}$ ) \\
\hline $\begin{array}{l}\text { Los partidos y movimientos políticos } \\
\text { que no participen en el Gobierno } \\
\text { podrán ejercer libremente la función } \\
\text { crítica frente a este y plantear y } \\
\text { desarrollar alternativas políticas. Para } \\
\text { estos efectos, salvo las restricciones } \\
\text { legales, se les garantizan los siguientes } \\
\text { derechos: de acceso a la información y a } \\
\text { la documentación oficiales; de uso de } \\
\text { los medios de comunicación social del } \\
\text { Estado de acuerdo con la represen- } \\
\text { tación obtenida en las elecciones para } \\
\text { Congreso inmediatamente anteriores; } \\
\text { de réplica en los medios de } \\
\text { comunicación del Estado frente a } \\
\text { tergiversaciones graves y evidentes o } \\
\text { ataques públicos proferidos por altos } \\
\text { funcionarios oficiales, y de participa- } \\
\text { ción en los organismos electorales. }\end{array}$ & $\begin{array}{l}\text { Los partidos y movimientos políticos } \\
\text { con personería jurídica que se declaren } \\
\text { en oposición al Gobierno, podrán ejercer } \\
\text { libremente la función crítica frente a } \\
\text { este, y plantear y desarrollar alternativas } \\
\text { políticas. Para estos efectos, se les } \\
\text { garantizarán los siguientes derechos: el } \\
\text { acceso a la información y a la } \\
\text { documentación oficial, con las } \\
\text { restricciones constitucionales y legales; } \\
\text { el uso de los medios de comunicación } \\
\text { social del Estado o en aquellos que hagan } \\
\text { uso del espectro electromagnético de } \\
\text { acuerdo con la representación obtenida } \\
\text { en las elecciones para Congreso } \\
\text { inmediatamente anteriores; la réplica en } \\
\text { los mismos medios de comunicación. }\end{array}$ \\
\hline $\begin{array}{l}\text { Los partidos y movimientos minorita- } \\
\text { rios tendrán derecho a participar en las } \\
\text { mesas directivas de los cuerpos } \\
\text { colegiados, según su representación en } \\
\text { ellos. }\end{array}$ & $\begin{array}{l}\text { Los partidos y movimientos minorita- } \\
\text { rios con personería jurídica tendrán } \\
\text { derecho a participar en las mesas } \\
\text { directivas de los cuerpos colegiados, } \\
\text { según su representación en ellos. }\end{array}$ \\
\hline $\begin{array}{l}\text { Una ley estatutaria regulará íntegra- } \\
\text { mente la materia. }\end{array}$ & $\begin{array}{l}\text { Una ley estatutaria reglamentará íntegra- } \\
\text { mente la materia. }\end{array}$ \\
\hline
\end{tabular}

